\title{
Rosalind Crone, Violent Victorians. Popular Entertainment in Nineteenth-Century London
}

New York and Manchester, Manchester University Press, 2012, 320 p., ISBN : 978-0-7190-8685-4

Dominique Kalifa

\section{(2) OpenEdition}

\section{Journals}

Édition électronique

URL : https://journals.openedition.org/chs/2619

DOI : $10.4000 /$ chs. 2619

ISSN : 1663-4837

Éditeur

Librairie Droz

Édition imprimée

Date de publication : 18 décembre 2019

Pagination : 139-140

ISSN : 1422-0857

Référence électronique

Dominique Kalifa, «Rosalind Crone, Violent Victorians. Popular Entertainment in Nineteenth-Century London ", Crime, Histoire \& Sociétés / Crime, History \& Societies [En ligne], vol. 23, n² | 2019, mis en ligne le 06 mai 2020, consulté le 02 avril 2022. URL : http://journals.openedition.org/chs/2619 ; DOI : https://doi.org/10.4000/chs.2619

Ce document a été généré automatiquement le 2 avril 2022.

(c) Droz 


\section{Rosalind Crone, Violent Victorians. Popular Entertainment in Nineteenth- Century London}

New York and Manchester, Manchester University Press, 2012, 320 p., ISBN : 978-0-7190-8685-4

\section{Dominique Kalifa}

\section{RÉFÉRENCE}

Rosalind Crone, Violent Victorians. Popular Entertainment in Nineteenth-Century London, New York and Manchester, Manchester University Press, 2012, 320 p., ISBN :

978-0-7190-8685-4

Du maître-livre de Richard Altick (Victorian Studies in Scarlet, 1972) à ceux, tout aussi majeurs de Peter Bailey (Leisure and Class, 1978), Francis Thompson (The Rise of Respectable Society, 1988), Vic Gatrell (The Hanging Tree, 1994), Martin Wiener (Men of Blood, 2004) et de dizaines d'autres auteurs, la question des relations de la culture victorienne à la violence a suscité une extraordinaire bibliographie. Il fallait donc une certaine audace à Rosalind Crone pour rouvrir ce dossier. La thèse qu'elle défend est évidemment recevable. En bref : le procès de normalisation et de "civilisation » des comportements des classes populaires, le redéploiement des sensibilités, l'intolérance accrue à la brutalité et le souci croissant de respectabilité, tous considérés de longue date comme des marqueurs décisifs de la culture victorienne, ne doivent pas être exagérés. Ni l'essor incontestable de la culture de l'honorabilité, ni le déclin avéré des violences interpersonnelles dans la Grande-Bretagne du XIX ${ }^{\mathrm{e}}$ siècle, n'ont vraiment endigué le goût public pour la violence, qui continue de prospérer dans les loisirs et les divertissements populaires. Pour Rosalind Crone, l'imaginaire victorien demeurait sanglant, et fut habilement exploité par des entrepreneurs qui en firent grand profit. 
2 Pour démontrer la persistance, voire l'expansion de cette culture, l'auteure avance, une fois planté le décor (Londres des années 1820-1870), cinq études de cas successives. La première retrace l'immense succès des spectacles de Punch \& Judy, deux marionnettes jamais avares de rixes, de bagarres et de coups de bâton, qui attiraient un vaste public goguenard dans les rues de la ville. Leur vogue déclina après 1840 , à peu près au moment où surgit le magazine satirique du même nom, destiné pour sa part à un public plus éduqué. La seconde étude empirique est consacrée à la culture de l'échafaud, elleaussi traditionnelle en Angleterre, mais qui ne cessa pas vraiment avant l'abolition des exécutions publiques en 1868. Elle revisite donc le continent immense et pour partie déjà exploré des broadsides, broadsheets, last-dying speeches, Old Bailey papers et autres biographies d'assassins et d'Highwaymen. Une troisième étude est consacrée aux mélodrames et innombrables penny gaffs qui pullulaient dans les rues de la capitale, tous ou presque centrés sur des meurtres ou des assassinats horribles. Un de ces spectacles fait l'objet d'un chapitre en soi, la terrifiante histoire du barbier de Fleet Street, Swenny Todd, qui égorgeait ses clients, les escamotait dans la cave, puis les découpait en morceaux revendus à sa voisine boulangère qui en faisait des pies. La dernière étude de cas concerne les hebdomadaires à sensation, principalement ceux produits et diffusés par Edward Lloyd (Lloyds' Weekly Newspaper, Penny Sunday Times), emplis d'innombrables récits de crimes, de massacres, de procès ou d'exécutions.

Dans chacun de ces chapitres, Rosalind Crone se montre précise et rigoureuse. Elle a su réunir des corpus originaux, met au jour des intrigues, des images ou des affiches révélatrices, discute avec droiture la bibliographie existante. Les développements consacrés aux éditeurs (Jemmy Catnach, Edward Lloyd), aux entrepreneurs de spectacles ou l'analyse comparée des récits de journaux constituent de substantiels apports. Que ces vieilles histoires soient "rechargées " par d'astucieux business men mid-victoriens dit bien leur importance. La faiblesse du livre vient d'ailleurs : comme elle avance avec honnêteté (c'est-à-dire en présentant et discutant les travaux de ses prédécesseurs), Crone peine à tracer son propre sillon dans un terrain aussi fréquenté. On sent à la lecture qu'elle a été partout gênée aux entournures, qu'elle a manqué de latitude. Des histoires comme celle de la Red Barn, des époux Manning ou de John Thurtell ont été si souvent racontées qu'on est embarrassé de les retrouver ici. Quant à la thèse, elle n'est ni vraie ni fausse : elle obéit à la classique histoire du verre d'eau, à moitié plein, ou à moitié vide, selon la perspective ou l'endroit d'où on l'examine. L'épilogue du livre en prend acte d'ailleurs en se contentant de retarder jusqu'aux années 1870 le turning point décisif signalant la victoire du contrôle social, la colonisation des formes les plus archaïques par les industries culturelles et l'avènement d'une société plus pacifiée. Mais sur la question des fonctions et usages de ces représentations persistantes de la violence, sur ce qui pourrait expliquer pourquoi une société « consomme » de tels récits, à quoi tient un tel public taste for violence, l'ouvrage ne peut en dire plus que les autres. Sans doute parce que la réponse n'appartient pas aux historiens. 


\section{AUTEURS}

\section{DOMINIQUE KALIFA}

Paris 1 Panthéon-Sorbonne

dominique.kalifa[at]univ-paris1.fr 